NBSIR 77-1229

\title{
Accelerometer Calibration -- A Comparison Between CESTA and NBS
}

James D. Pollard

Engineering Mechanics Section Mechanics Division Institute for Basic Standards National Bureau of Standards

Washington, D.C. 20234

January 1977

Final

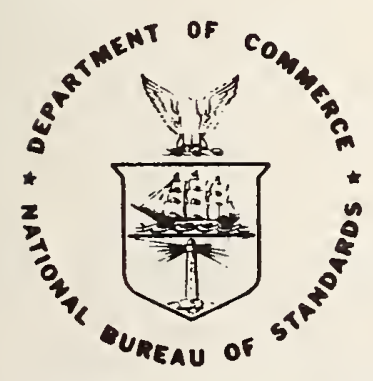

U. S. DEPARTMENT OF COMMERCE NATIONS L BUREAU OF STANDARDS 

NBSIR 77-1229

\section{ACCELEROMETER CALIBRATION -- \\ A COMPARISON BETWEEN \\ CESTA AND NBS}

James D. Pollard

Engineering Mechanics Section

Mechanics Division

Institute for Basic Standards

National Bureau of Standards

Washington, D.C. 20234

January 1977

Final

U.S. DEPARTMENT OF COMMERCE, Juanita M. Kreps, Secretary

Dr. Betsy Ancker-Johnson, Assistant Secretary for Science and Technology

NATIONAL BUREAU OF STANDARDS, Ernest Ambler, Acting Director 

1. INTRODUCTION

2. DESCRIPTION OF EQUIPMENT

3. COMPARISON TEST DESCRIPTION

4. INTERFEROMETER TEST DESCRIPTION

5. METHOD OF TEST

6. RESULTS OF TEST - SYSTEM 1

7. RESULTS OF TEST - SYSTEM 2

8. UNCERTAINTY OF RESULTS

9. CONCLUSIONS

10. ACKNOWLEDGEMENTS

11. REFERENCES 


\section{TABLES}

1. Results of comparison calibration of System 1 .

Page

2. Summary of comparative test results for System 1.

3. Results of interferometric measurements of System 1.

4. Results of comparison calibration of System 2.

5. Summary of comparative test results for System 2 .

6. Results of interferometric measurements of System 2 .

\section{ILLUSTRATIONS}

Page

Figure 1. Sensitivity of System 1 .

Figure 2. Sensitivity of System 2. 


\title{
ACCELEROMETER CALIBRATION -- \\ A COMPARISON BETWEEN CESTA AND NBS
}

\author{
James D. Pollard
}

\begin{abstract}
This report describes a vibration measurement interchange between a French laboratory (CESTA) and the National Bureau of Standards (NBS). Methods of calibration at NBS and results of the calibration of two commercially available double ended or "piggy-back" type accelerometers are discussed. No difficulties were encountered in the calibration of System 1, however, above $4000 \mathrm{~Hz}$ difficulties were experienced in the calibration of system 2 .

Key Words: Accelerometers; calibration; measurements; vibration; vibration exciters; vibration standards.
\end{abstract}

\section{INTRODUCTION}

The measurement techniques of individual laboratories charged with the calibration of physical standards for measurement of vibration differ considerably. This report describes a measurement interchange, involying vibration measuring instruments, between the National Bureau of Standards (NBS) and a French national laboratory within the Aquitaine Center for Scientific and Technical Studies (CESTA).

\section{DESCRIPTION OF EQUIPMENT}

Two commercially available, laboratory quality accelerometers and their associated charge amplifiers were used in these tests. These accelerometers are used as transfer standards and are of the double-ended or "piggy-back" type. One of the transfer accelerometers was manufactured in the United States and the other was manufactured in Europe. In this report these shall be referred to as System 1 and System 2, respectively.

A precision piezoelectric quartz accelerometer system was used as a reference standard. This system was periodically calibrated and maintained as a standard by the National Bureau of Standards. Although it had been calibrated in April 1976, it was recalibrated just prior to these tests, and the sensitivity factors used to reduce the data were adjusted to consider the slight drift shown by the history of the system. 
One of the transfer standards (System 1) has a 1/4-28 UNF mounting hole at the upper end. A 1/4-28 to 10-32 adaptor stud which provided a definite thread depth for both accelerometers was used. The other transfer standard accelerometer (System 2) had a 10-32 UNF mounting hole at the upper end. A cable with a length of seven meters and a measured capacitance of 810.9 picofarads was furnished by CESTA and was used with the transfer systems throughout the tests.

The electrical connections for each accelerometer were cleaned and the connectors were securely attached. The cables were taped to the vibration generator as close to the accelerometer connections as possible without interfering with the motion. During the entire test period, line power was left applied to the charge amplifiers and all measuring equipment.

In all instances, the accelerometer outputs were applied to a charge sensing amplifier. For System 1 and System 2, two separate but identical model number charge amplifiers were used. These amplifiers were manufactured in France and their gain was nominally $1000 \mathrm{mV} / \mathrm{pC}$. The NBS amplifier had a gain of nominally $10 \mathrm{mV} / \mathrm{pC}$. The frequency-gain response of each of the test amplifiers was measured and used in the data analysis. Problems were encountered in the gain measurements and insufficient time was available to resolve the problems and to assess the amplifier gain measurement uncertainty.

The transfer standard accelerometers (System 1 and 2) had been calibrated by the French laboratory just prior to their arrival at NBS and more tests were to be made upon their return to CESTA.

\section{COMPARISON TEST DESCRIPTION}

The CESTA transfer standard accèlerometers (System 1 and 2) were calibrated by a comparison method using an NBS accelerometer as a reference standard. The reference accelerometer was mounted on top of each of the test accelerometers throughout the comparison calibration. The accelerometers were attached with a stud which permitted the mating surfaces to be in direct contact with each other and were tightened with a torque of nominally $2 \mathrm{Nm}$. Two Dimoff Vibration Standards [1]* were used as vibration exciters.

An automated comparison calibration facility at NBS is used to calibrate accelerometers on a routine basis [2]. A software program in a mini-computer controls the entire test process. The program contains codes which are translated into frequencies and voltages by a programmable oscillator which in turn supplies a input to a power amplifier. This then drives the vibration exciter. At each test frequency there is a preset acceleration level which is program controlled through a closed-loop process to insure that this level remains constant.

$*$ Numbers in brackets correspond to references given at the end of this report. 
Since the charge amplifiers used with the transfer standard accelometers had high outputs, the automated system calculated the sensitivity factors using the relationship:

$$
S_{t}=S_{S} R
$$

where $\mathrm{S}_{t}=$ sensitivity of the transfer accelerometer,

$S_{S}=$ sensitivity of the reference accelerometer, and

$\mathrm{R}$ = ratio of the transfer accelerometer voltage to the reference accelerometer voltage,

$$
\mathrm{R}=\frac{\text { Transfer accelerometer voltage }}{\text { Reference accelerometer voltage }} .
$$

The system sensitivity factors are the open circuit output of the charge amplifier in millivolts per unit acceleration in $\mathrm{g} *(\mathrm{mV} / \mathrm{g})$. The automated system is capable of measuring these ratios to within a few tenths of one percent.

The waveform of each accelerometer's charge amplifier output was monitored on an oscilloscope. The waveform harmonic distortion generally did not exceed one-percent. The transverse motion ratio, although not monitored, is believed to be less than one percent over most of the frequency range under normal exciter load conditions. Lateral resonances at a few narrow frequency bands may cause the transverse motion ratio to be greater than one percent, but how much greater is not known.

\section{INTERFEROMETER TEST DESCRIPTION}

The normal method used to calibrate accelerometers on piezoelectric exciters is that of a modulated photoelectric measurement of amplitude utilizing a Fizeau interferometer and a fringe disappearance technique [3]. The light source is a HeNe laser. A small reflector is attached to the vibrating surface to be measured. The upper interferometer plate, a plano-convex lens, is mounted just above the plane reflector. In order to induce a low modulating frequency of vibration in the upper plate, a small piezoelectric mass-reaction exciter is mounted on the lens support and is driven at a frequency of about $100 \mathrm{~Hz}$. A photodetector views the center fringe and produces a signal which is applied to a narrow-band filter which is phase locked to the $100 \mathrm{~Hz}$ modulating frequency.

In this study, units of acceleration are expressed in gravitational units of $\mathrm{g}$. This was done to facilitate communication with the intended reader. Conversion to SI units may be accomplished by using the relationship $1 \mathrm{~g}=9.80665 \mathrm{~m} / \mathrm{s}^{2}$. 
In operation, the main exciter is first left at rest and the modulating frequency is induced in the upper plate. The amplitude of the modulating vibration is adjusted to bring the photodetector output to its first maximum. The mean mirror separation is then adjusted to further maximize the output. Control of the mirror separation is achieved by superimposing a dc bias on the ac driving signal to the modulating exciter. The main exciter on which the accelerometer is mounted is then driven to an amplitude which causes the photodetector signal to drop to a very distinct null (fringe disappearance). The output of the accelerometer is measured at this time to give one calibration point. Sensitivity factors are computed from values of displacement amplitude, frequency, and output voltage of the charge amplifier. For the system used, fringe disappearance occurs at a double displacement amplitude of $242.2 \mathrm{~nm}$ $(9.536 \mu$ in).

Measurements on the CESTA accelerometers were made by cementing a mirror onto the upper mating surfaces of each of the accelerometers. Data obtained from this test cannot be compared directly to the results from the comparison test described earlier. The "piggy-back" type acce1erometers exhibit a mass-loading sensitivity, that is, their sensitivity changes as a function of the mass, and geometry of that mass, which is mounted on the upper surface. Normally, this "mass" is another accelerometer to be calibrated. However, in this test the "mass" is only a sma11 glass mirror. The mass loading effect is-generally larger at frequencies greater than 2 or $3 \mathrm{kHz}$. The values obtained from this test apply only under the conditions of this test. No methods have yet been developed which allow interferometric measurements to be made on double-ended, piggy-back type accelerometers with realistic mass loading conditions. However, it is possible to compare results obtained from two laboratories under the same mass loading conditions (i.e., with a mirror only as the mass). At the conclusion of the NBS testing the mirrors were left attached to the two CESTA accelerometers so they could be tested using a similar procedure at the French 1aboratory. Only then can any comparisons be made between the NBS and CESTA results using this type of measurement technique.

\section{METHOD OF TEST}

A comparison calibration on the NBS automated system, consisted of two runs from 10 to $10000 \mathrm{~Hz}$ on one of the two NBS vibration generators. Data was taken at $10,15,30,50$, and $100 \mathrm{~Hz}$ at $100 \mathrm{~Hz}$ increments between 100 and $1000 \mathrm{~Hz}$ and at $500 \mathrm{~Hz}$ increments between 1000 and 10000 $\mathrm{Hz}$. After completion of a test, the entire assembly, consisting of the reference standard, stud and transfer standard was removed, mounted onto the second vibration generator and tested as above. The entire test was then repeated. This yielded four sets of data for the system. Both systems were subjected to the same cycle of testing. Both systems were once again tested in the same manner. At the conclusion of the comparison test program each system had been calibrated 8 times at 33 frequencies giving a total of 264 data points per system. 
The interferometric test consisted of four data points at each of 20 frequencies between 1000 and $10000 \mathrm{~Hz}$ in $500 \mathrm{~Hz}$ increments. Two different exciters were used with a repeat test on one of the exciters. This yielded a data set of 240 measurement points.

\section{RESULTS OF TEST - SYSTEM 1}

Table 1 presents the data and the average for each of the data points resulting from testing on each of the two NBS Dimoff Vibration generators. The four data points from each generator were averaged to yield the value of sensitivity for each of the test frequencies. The data presented are system sensitivity factors $(\mathrm{mV} / \mathrm{g})$. These factors were determined by comparing the voltage output of the charge amplifier used with the transfer standard accelerometer to the output of the reference standard.

Table 2 presents a summary of the comparison calibration data for System 1. The average data from the two Dimoff exciters are in column 2 and 3. Column 4 is the overall mean. Column 5 gives the factors used to adjust the reference system sensitivity factor to account for the calibration history of the system, and column 6 is the corrected transfer system sensitivity factor. Column 7 is the gain of the charge amplifier used with System 1. To present the results also in terms of the charge sensitivity of the accelerometer, the system sensitivity was divided by the amplifier gain. The results of this are in the last column. The accelerometer sensitivity factor is the output of the accelerometer in picocoulombs per unit acceleration in $\mathrm{g}(\mathrm{pC} / \mathrm{g})$. Figure 1 is a graph of the system sensitivity. It is believed that whipping of the cable, which generates spurious signals due to triboelectric effect, and the poor signal-to-noișe ratio of the test charge amplifier were responsible for the 10 and 15 hertz points showing an unexpected rise.

Table 3 presents the results of the interferometric testing. Columns 2, 3, and 4 are the average of the four data points from the three runs. Column 5 is the overall average of all the data. Column 6 gives the charge amplifier gain in units of millivolts per picocoulomb (mV/pC). The last column is the result of dividing the system sensitivity (column 5 ) by the gain to give accelerometer sensitivity in units of picocoulombs per $g(\mathrm{pC} / \mathrm{g})$.

A comparison of the data generated during these tests with informal CESTA data showed that, in the frequency range of 30 to $7000 \mathrm{~Hz}$ (which is the upper limit of the CESTA measurements), the NBS data generally averaged a difference of less than one percent from the CESTA mean. The NBS data was lower at each of the test frequencies. Above $7000 \mathrm{~Hz}$, the NBS data indicated a rise of about three percent at $10000 \mathrm{~Hz}$. The slight variations in response between 2500 and $7000 \mathrm{~Hz}$ are believed to be caused by interactions between the reference and transfer standard as an assembly. 


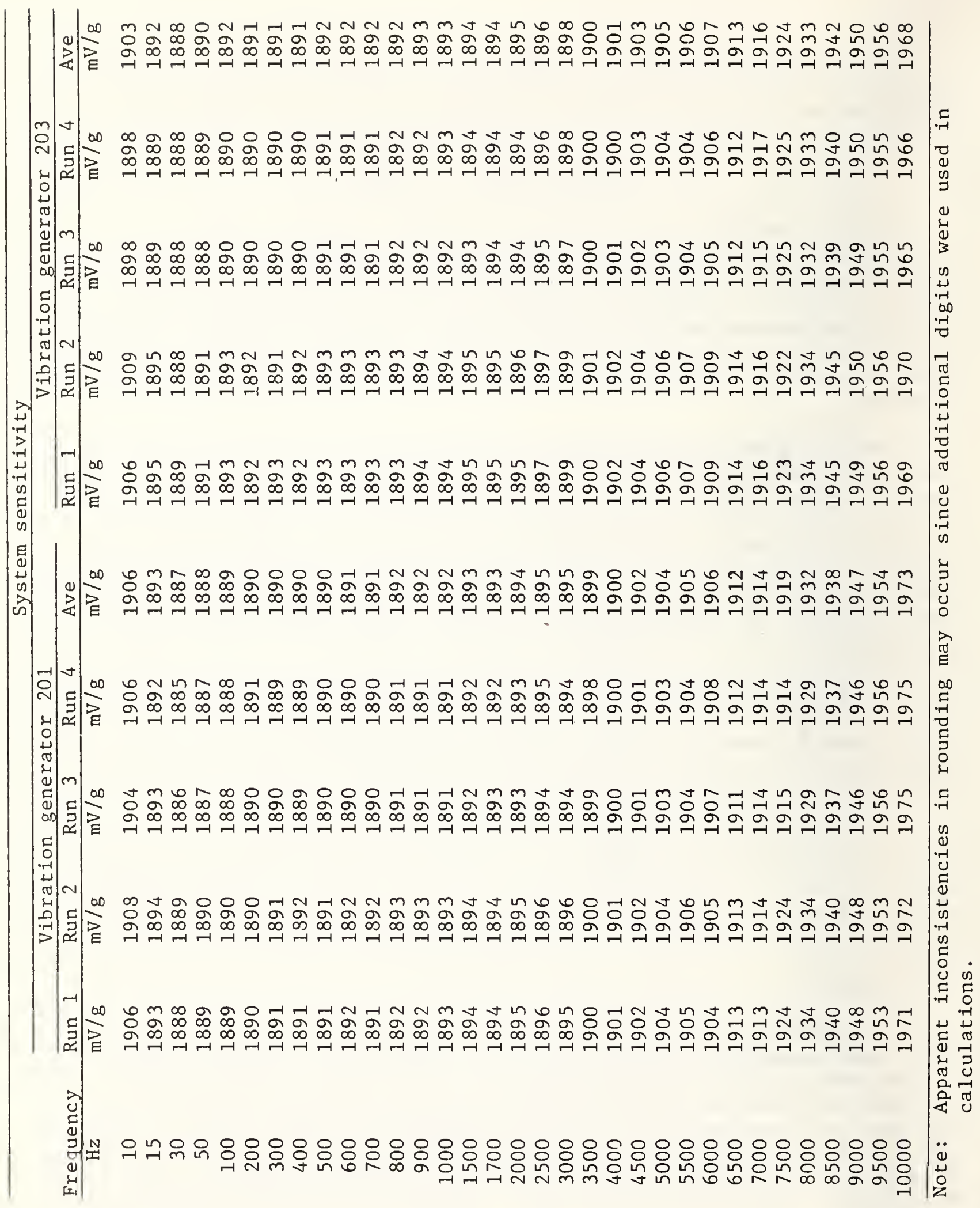




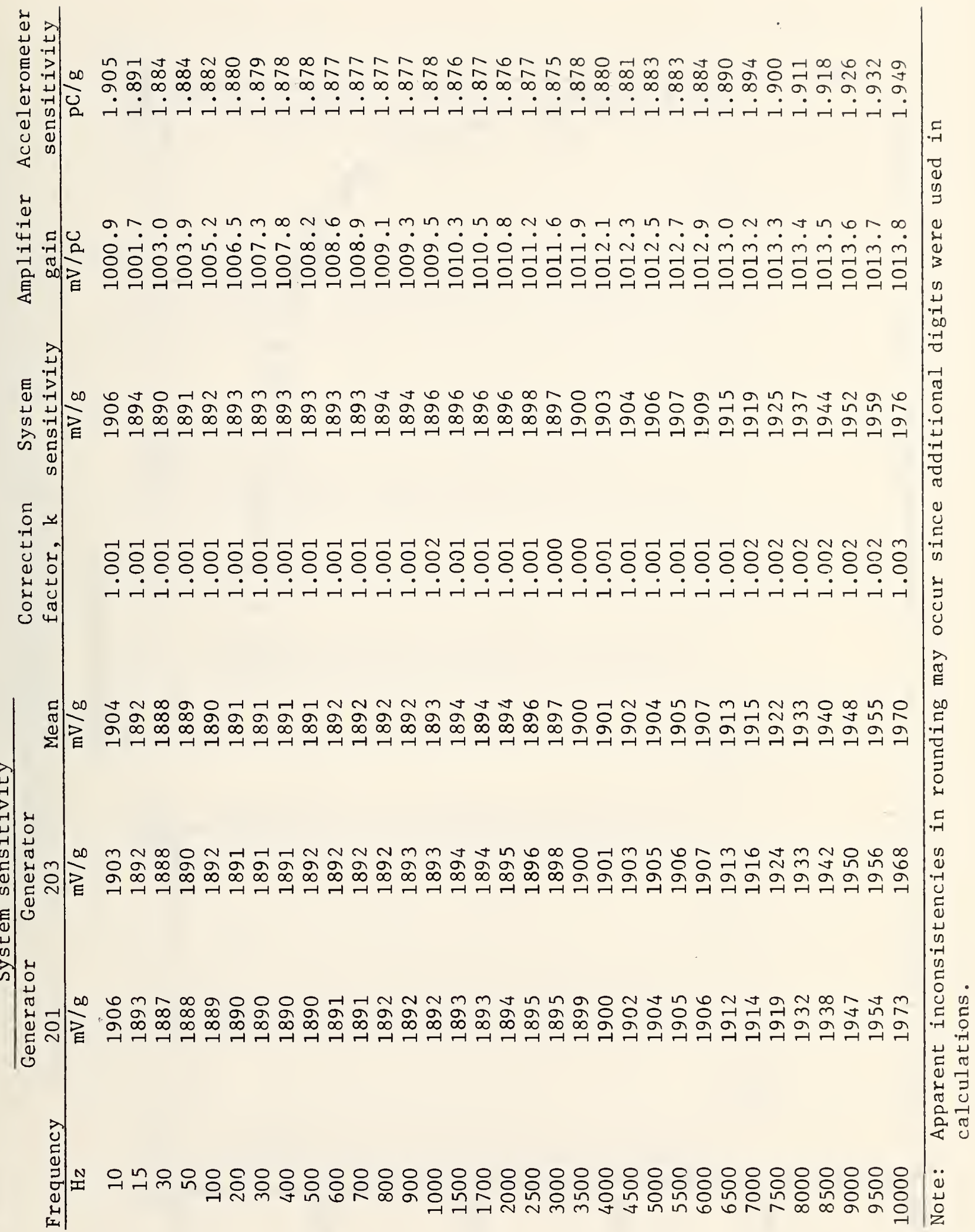




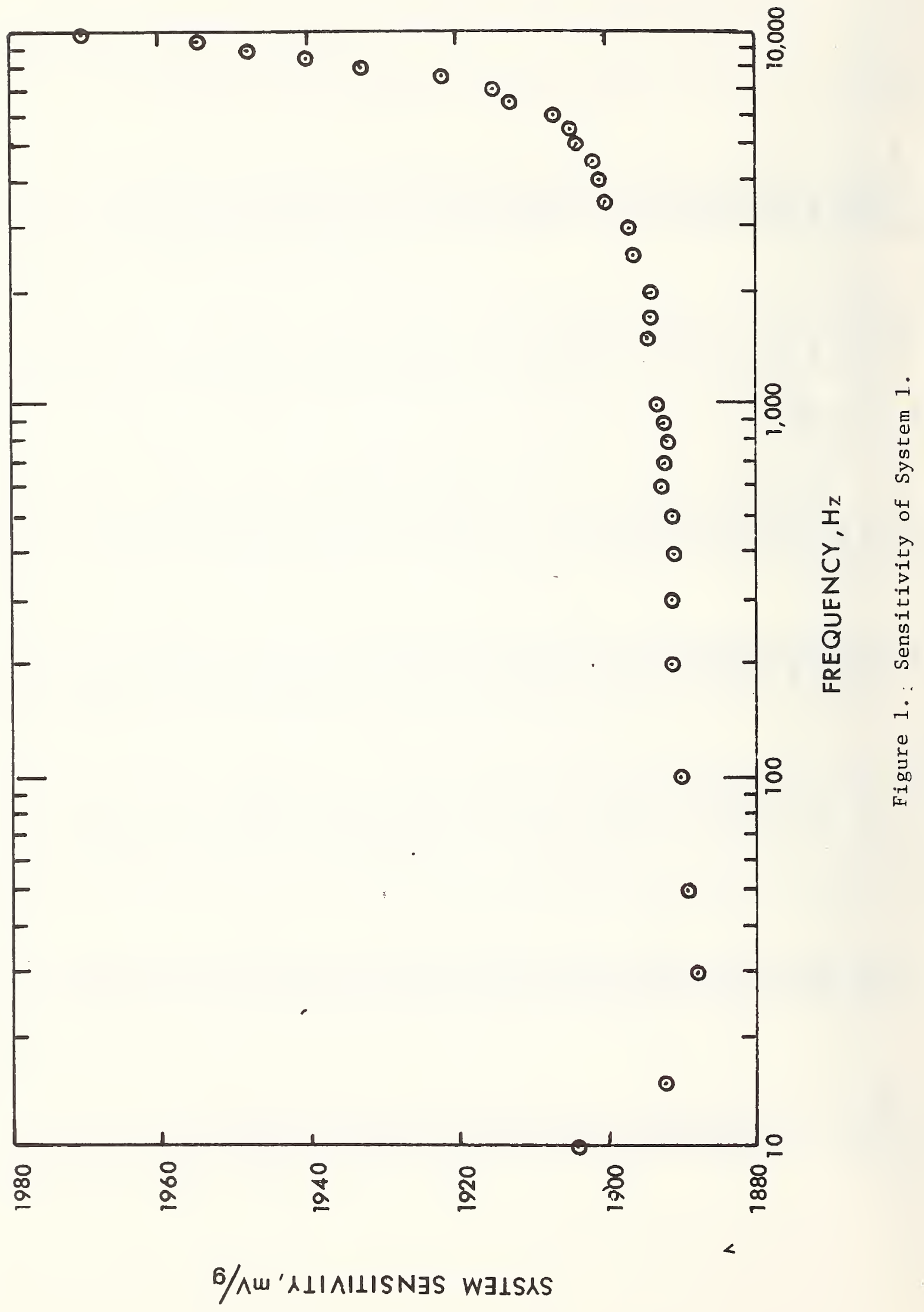




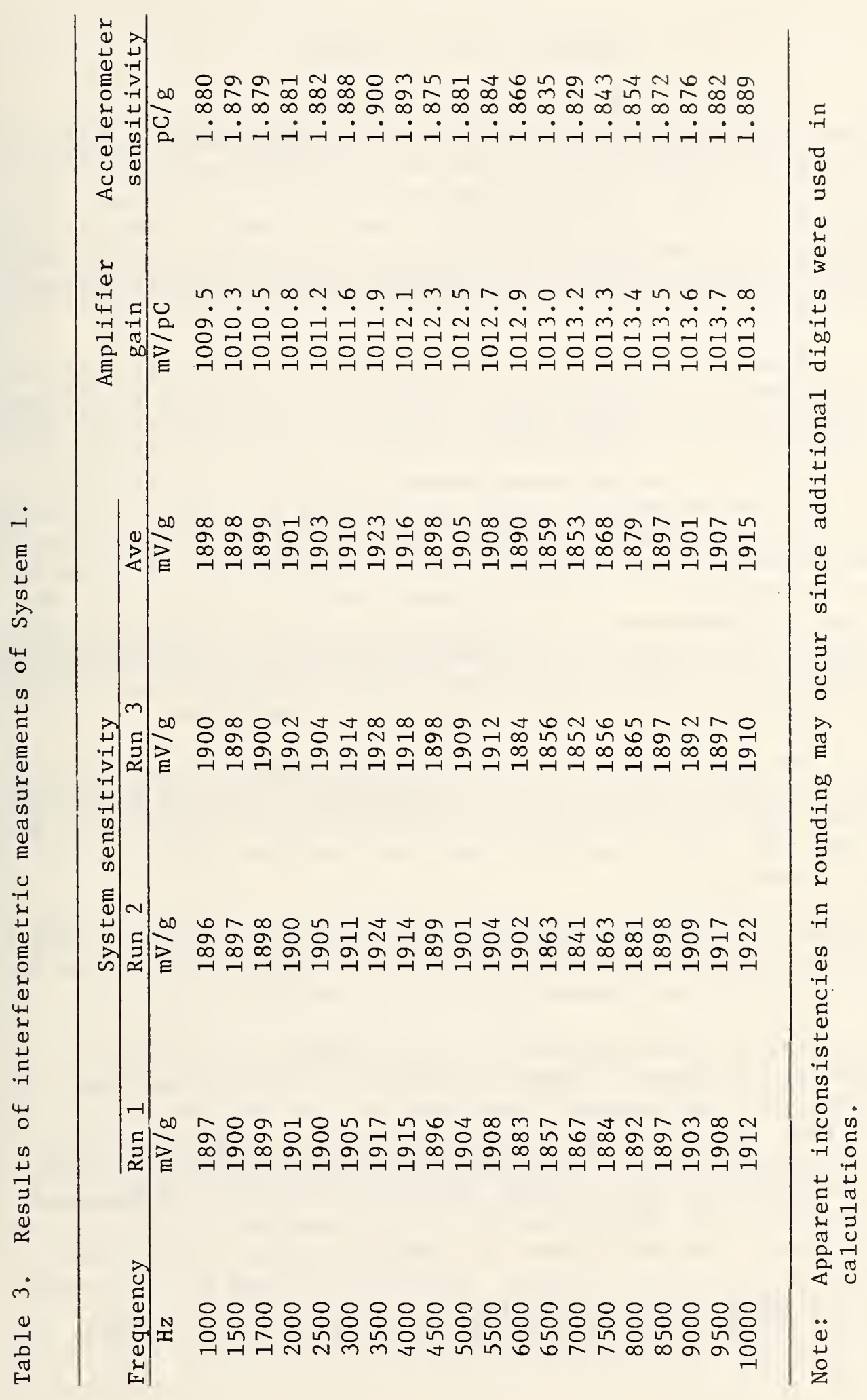




\section{RESULTS OF TEST - SYSTEM 2}

Table 4 presents the data and the average for each data point resulting from testing System 2 on each of the two NBS Dimoff Vibration generators. The four data points from each generator were averaged to yield the value of sensitivity for each of the test frequencies. The data presented are the system sensitivity factors ( $\mathrm{mV} / \mathrm{g}$ ). These factors were determined by comparing the voltage output of the charge amplifier used with the transfer standard accelerometer with the output of the reference standard.

Table 5 presents a summary of the comparison calibration data for System 2. The average data from the two Dimoff exciters is in column 2 and 3. Column 4 is the overall mean. Column 5 is the correction factor used to account for the calibration history of the reference system, and column 6 is the corrected system sensitivity factor. Column 7 is the gain of the charge amplifier used with System 2. Again, to present the results also in terms of the charge sensitivity of the accelerometer, the system sensitivity was divided by the amplifier gain. The results of this are in column 8. The accelerometer sensitivity factor is the output of the accelerometer in picocoulombs per unit acceleration in $g$ $(\mathrm{pC} / \mathrm{g})$. Figure 2 is a graph of the system sensitivity. The unexpected rise at 10 and 15 hertz is again believed to be caused by cable motion and the poor signal-to-noise ratio of the charge amplifier.

Table 6 presents the results of the interferometric testing. As with System 1, column 2, 3, and 4 are the average of four data points from the three runs. Column 5 is the overall average of all of the data. Column 6 gives the charge amplifier gain, and the last column is the accelerometer sensitivity.

The results of the calibration of this transfer standard at NBS compare closely with informal CESTA data in the range of 30 to $3000 \mathrm{~Hz}$. The results from the two laboratories tend to overlap very well.

Difficulties were encountered in the calibration of System 2. Results indicated a difference, when mounted on the two NBS exciters, of 1 to 2.5 percent in the response above $4000 \mathrm{~Hz}$. It had been noted during check-in of this equipment that the upper and lower surfaces of this accelerometer were badly scarred. Time was expended in refinishing these surfaces. An additional run on both exciters indicated an improvement in the response but the differences were still considerably greater than usually expected. This can be seen by comparing these results with the corresponding results from System 1 . The data included in this report is the data obtained after refinishing. 


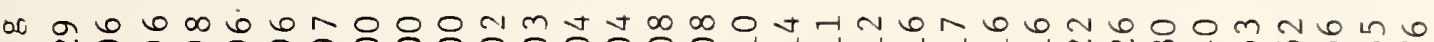

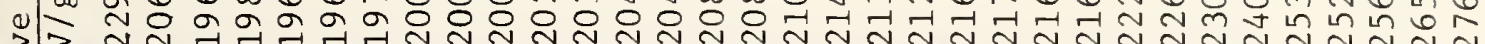
य ह न म

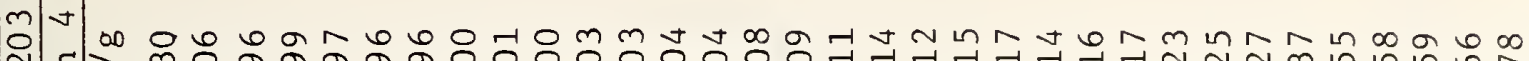
N

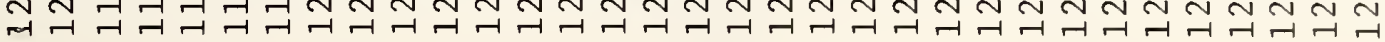

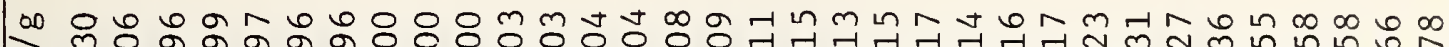
m

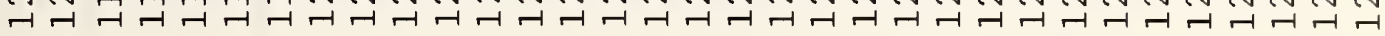

an $\infty N-N G$ N

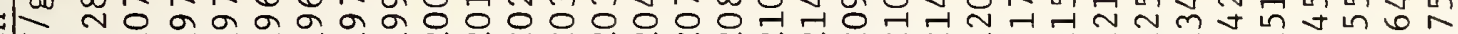

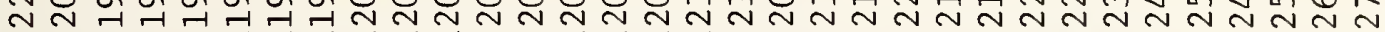

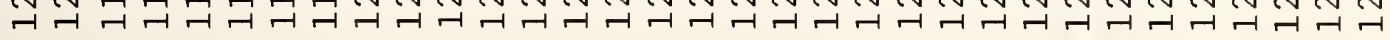

$-1+\infty \quad \infty$

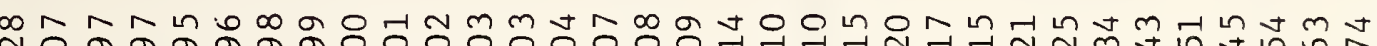

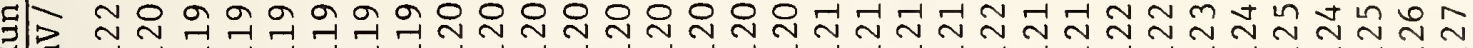

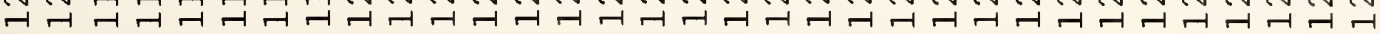

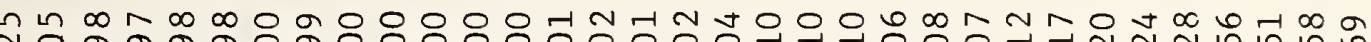

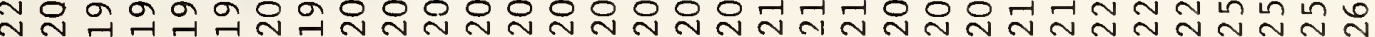

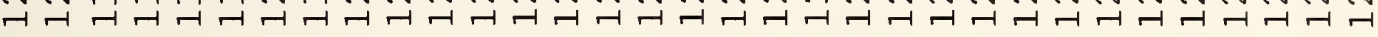

-

이 Nㅐ 개 त्म

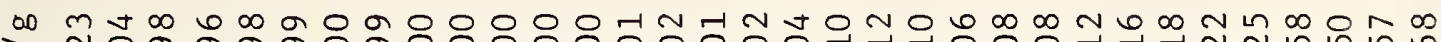

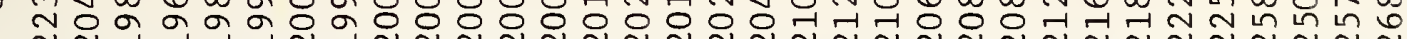
ᄃี $\rightarrow-1$ 닐

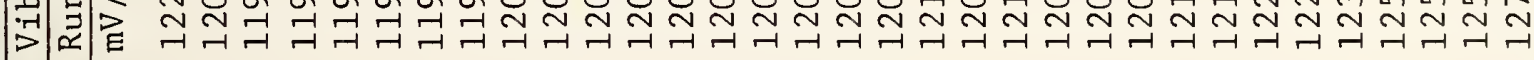

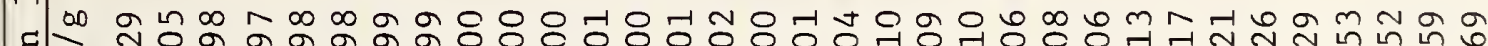

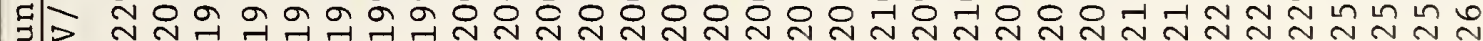

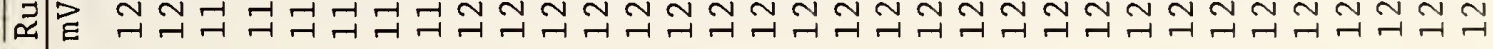

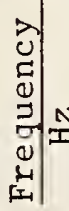




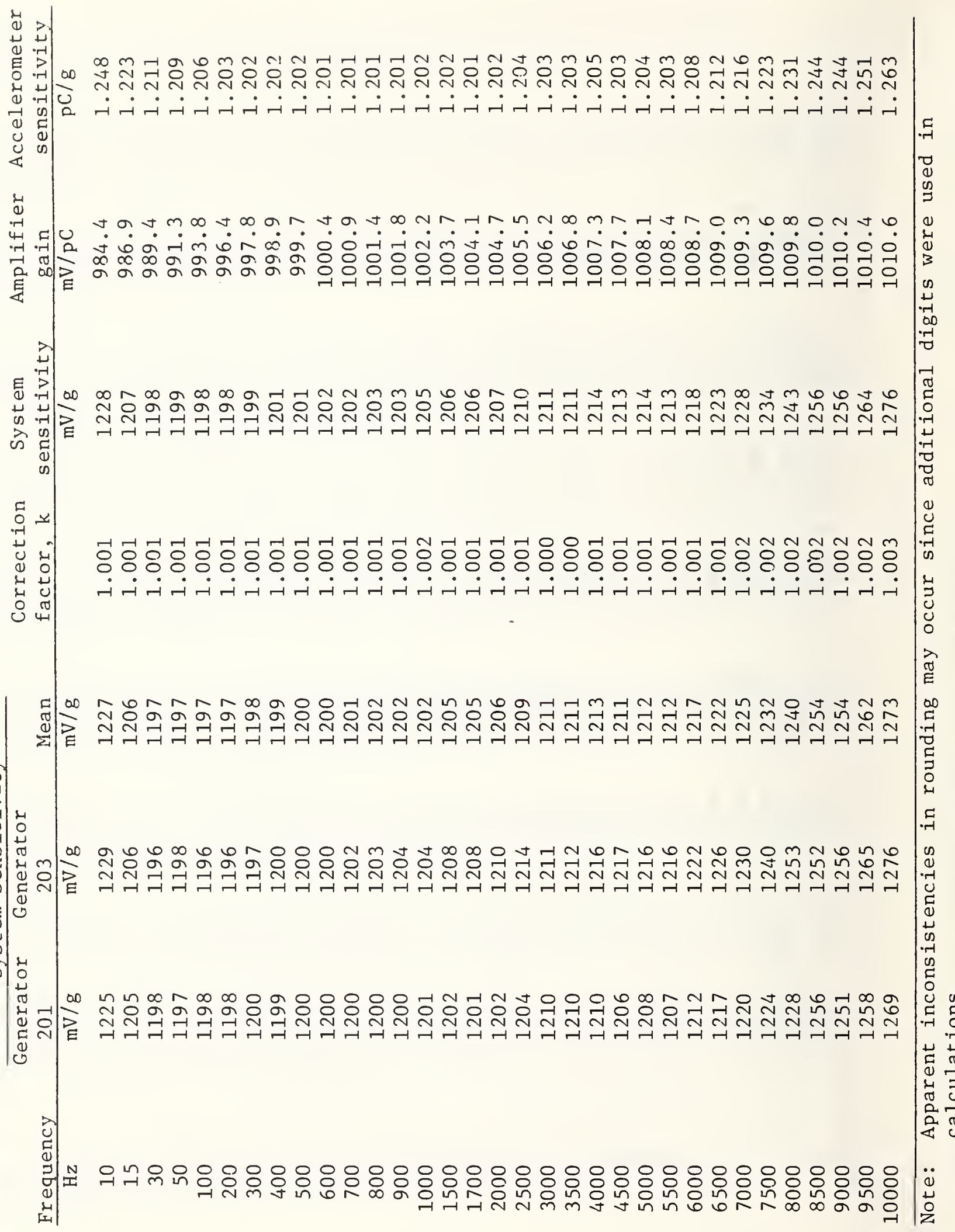




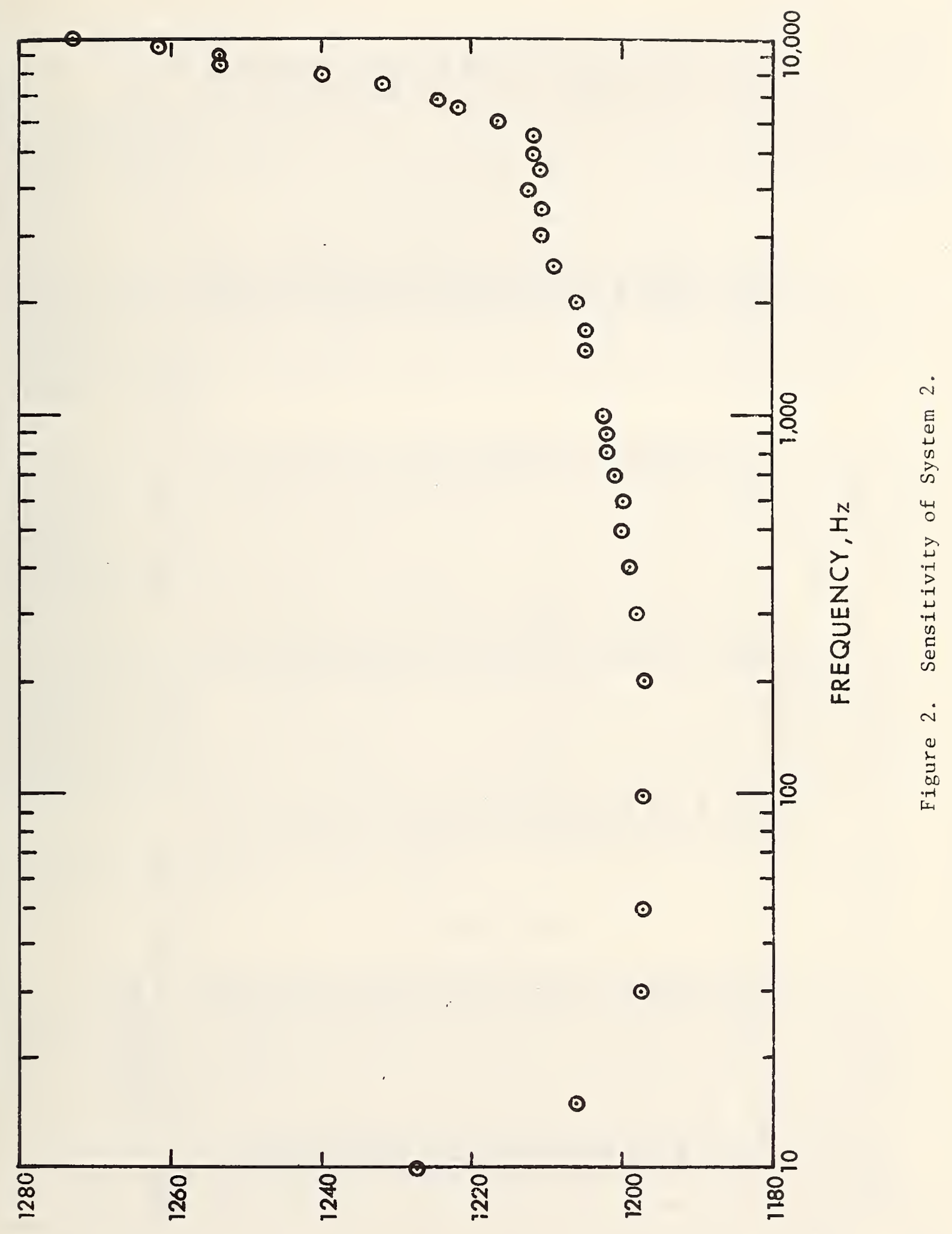

6/Am 'ALIAILISNGS WJISAS 


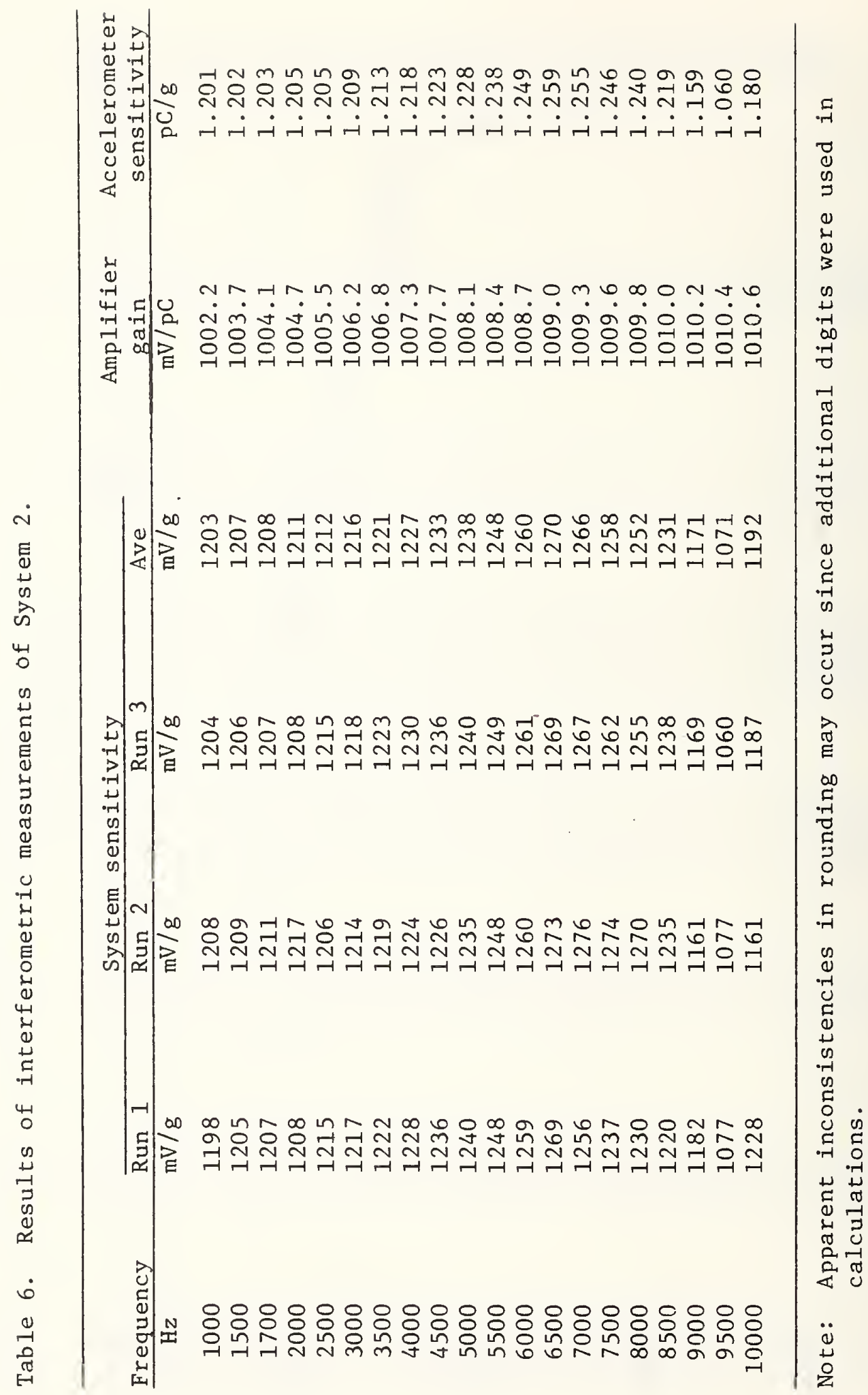


The NBS laboratory had available another accerlerometer of this same type. This was substituted for the CESTA System 2 accelerometer and data taken. This second accelerometer did not exhibit any such deviation in the response above $4000 \mathrm{~Hz}$. The reason for the problem in the CESTA accelerometer was not determined. Additional testing should be performed at the French laboratory to determine the cause of this anomalous behavior.

\section{UNCERTAINTY OF RESULTS}

The calibration procedures followed at NBS will generally give system sensitivities $(\mathrm{mV} / \mathrm{g}$ ) with uncertainties of not more than one percent over the frequency range of 10 to $1000 \mathrm{~Hz}$ and two percent from 1000 to $10000 \mathrm{~Hz}$. An additional uncertainty of about 0.25 percent would be expected in measuring amplifier gain and converting to accelerometer sensitivity $(\mathrm{pC} / \mathrm{g})$.

In the tests covered here, the amplifier noise level and possible triboelectric effects due to cable whipping have introduced a significant, but unevaluated, additional uncertainty at 10 and $15 \mathrm{~Hz}$. The problem encountered with System 2 (Section 7) also added to the uncertainty of the results for this system above $4000 \mathrm{~Hz}$. Since the effects of these problems were not determined, an estimate of uncertainty at 10 and $15 \mathrm{~Hz}$ and, for system 2, at the higher frequencies cannot be given.

Examination of the results of the amplifier gain measurements has shown them to be less consistent than expected. It is not known whether this problem was a result of the amplifier behavior or of the gain measurement process. Unfortunately, the systems were not available at NBS long enough for these factors to be resolved. As a result, the accelerometer sensitivities also contain an additional, unevaluated uncertainty, and no value of this uncertainty can be given.

With the exceptions noted above, the usual uncertainties can be assigned to the results of these tests.

\section{CONCLUSIONS}

The results should be considered valid only for the methods and hardware tested. Although there was general agreement with the limited, informal CESTA data that was available, several things do remain unexplained. For example, the almost constant difference between the NBS measurements and the CESTA measurements of System 1, and the problem of System 2 above $4000 \mathrm{~Hz}$. In the first case, the results agree within the claims of both laboratories and the difference may be in the measurement techniques employed and the random and systematic errors expected. Certain interactions between the particular units tested are difficult to ascertain and might have had an effect. Some of these might have been column resonances of the reference and transfer standards as a column assembly, relative motion between the upper and lower surfaces of the transfer standard, strain sensitivity of the transfer standard, noise, etc. The problem with System 2 above $4000 \mathrm{~Hz}$ remains unexplained. 


\section{ACKNOWLEDGEMENTS}

The writer wishes to thank Roscoe L. Bloss, Chief, Engineering Mechanics Section, for his assistance in the preparation of this report. Thanks also to John D. Ramboz for his guidance and help. Oliver W. Price is thanked for obtaining the interferometric data. A special note of appreciation from the entire NBS team to Jean Fromentin of CESTA for a most enlightening and free exchange of information during this visit. 


\section{REFERENCES}

[1] Dimoff, T., "Electrodynamic Vibration Standard with a Ceramic Moving Element", Journal of the Acoustical Society of America, Vo1. 40, No. 3, Sept. 1966, pp. 671-676.

[2] Payne, B. F., "An Automated Precision Calibration System for Accelerometers", Instrument Society of America 17th National Aerospace Instrumentation Symposium, May 1971.

[3] Schmidt, V. A., Edelman, S., Smith, E. R., and Pierce, E. T., "Modulated Photoelectric Measurement of Vibration", Journal of the Acoustical Society of America, Vol. 34, No. 4, April 1962, pp. 455458 . 
NBS-114A IREV.7-73

\begin{tabular}{|c|c|c|c|}
\hline $\begin{array}{l}\text { U.S. DEPT. OF COMM. } \\
\text { BIBLIOGRAPHIC DATA } \\
\text { SHEET }\end{array}$ & $\begin{array}{l}\text { 1. PUBLICATION OR REPORT NO. } \\
\text { NBSIR 77-1229 }\end{array}$ & $\begin{array}{l}\text { 2. Gov't Accession } \\
\text { No. }\end{array}$ & 3. Recipient's Accession No. \\
\hline \multicolumn{3}{|l|}{ 4. TITLE AND SUBTITIE } & $\begin{array}{l}\text { 5. Publication Date } \\
\text { March } 1977\end{array}$ \\
\hline \multicolumn{3}{|c|}{$\begin{array}{l}\text { Accelerometer Calibration -- } \\
\text { A Comparison Between CESTA and NBS }\end{array}$} & 6. Performing Organization Code \\
\hline \multicolumn{3}{|l|}{$\begin{array}{l}\text { 7. AUTHOR(S) } \\
\text { James D. Pollard }\end{array}$} & 8. Performing Organ. Report No. \\
\hline \multirow{2}{*}{\multicolumn{3}{|c|}{$\begin{array}{l}\text { 9. PERFORMING ORGANIZATION NAME AND ADDRESS } \\
\text { NATIONAL BUREAU OF STANDARDS } \\
\text { DEPARTMENT OF COMMERCE } \\
\text { WASHINGTON, D.C. } 20234\end{array}$}} & $\begin{array}{l}\text { 10. Próject/Task/Work Unit No. } \\
2130149\end{array}$ \\
\hline & & & 11. Contract/Grant No. \\
\hline \multirow{2}{*}{\multicolumn{3}{|c|}{ 12. Sponsoring Organization Name and Complete Address (Street, City, State, ZIP) }} & $\begin{array}{l}\text { 13. Type of Report \& Period } \\
\text { Covered } \\
\text { Final }\end{array}$ \\
\hline & & & 14. Sponsoring Agency Code \\
\hline
\end{tabular}

\section{SUPPLEMENTARY NOTES}

16. ABSTRACT (A 200-word or less factual summary of most significant information. If document includes a significant bibliography or literature survey, mention it here.)

This report describes a vibration measurement interchange between a French laboratory (CESTA) and the National Bureau of Standards (NBS). Methods of calibration at NBS and results of the calibration of two commercially available double ended or "piggy-back" type accelerometers are discussed. No difficulties were encountered in the calibration of System 1, however, above $4000 \mathrm{~Hz}$ difficulties were experienced in the calibration of System 2 .

17. KEY WORDS (six to twelve entries; alphabetical order; capitalize only the first letter of the first key word unless a proper name; separated by semicolons)

Accelerometers; calibration; measurements; vibration; vibration exciters;

vibration standards.

18. AVAILABILITY $\mathrm{x}$ Unlimited

For Official Distribution. Do Not Release to NTIS

Order From Sup. of Doc., U.S. Government Printing Office

Washington, D.C. 20402, SD Cat. No. C13

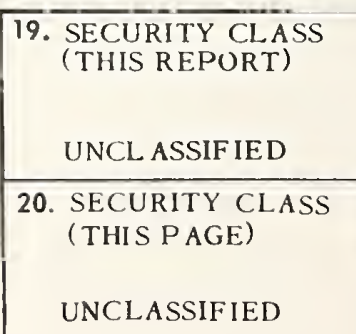

21. NO. OF PAGES

Order Irom National Technical Information Service (NTIS)

Springfield, Virginia 22151

UNCLASSIFIED

21

22. Price

$\$ 3.50$ 